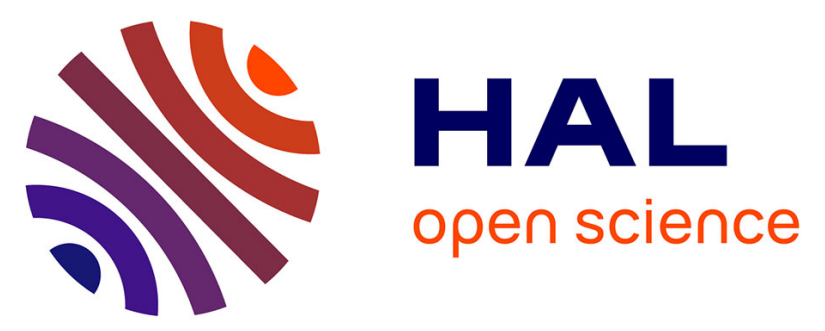

\title{
Is ultrasound-guided caudal steroid injection effective in the management of lower lumbar radicular pain? A two-center prospective observational study on 150 patients
}

François Robin, Guillaume Coiffier, Jean-David Albert, Christelle

Darrieutort-Laffite, Simon Rio, Benoit Le Goff, Pascal Guggenbuhl

\section{To cite this version:}

François Robin, Guillaume Coiffier, Jean-David Albert, Christelle Darrieutort-Laffite, Simon Rio, et al.. Is ultrasound-guided caudal steroid injection effective in the management of lower lumbar radicular pain? A two-center prospective observational study on 150 patients. Joint Bone Spine, 2020, 87 (4), pp.364-365. 10.1016/j.jbspin.2019.11.006 . hal-02442527

HAL Id: hal-02442527

https://hal-univ-rennes1.archives-ouvertes.fr/hal-02442527

Submitted on 29 Jan 2020

HAL is a multi-disciplinary open access archive for the deposit and dissemination of scientific research documents, whether they are published or not. The documents may come from teaching and research institutions in France or abroad, or from public or private research centers.
L'archive ouverte pluridisciplinaire HAL, est destinée au dépôt et à la diffusion de documents scientifiques de niveau recherche, publiés ou non, émanant des établissements d'enseignement et de recherche français ou étrangers, des laboratoires publics ou privés. 
Is ultrasound-guided caudal steroid injection effective in the management of lower lumbar radicular pain? A two-center prospective observational study on 150 patients

François Robin ${ }^{1,2}$, Guillaume Coiffier ${ }^{1,2}$, Jean-David Albert ${ }^{1,2}$, Christelle Darrieutort-Laffite ${ }^{3}$, Simon Rio $^{1}$, Benoit Le Goff ${ }^{3}$, Pascal Guggenbuhl ${ }^{1,2}$

(1)Department of Rheumatology, CHU de RENNES, Rennes, France

(2)University of Rennes, INSERM NuMeCan UMR 1274, CIMIAD, Rennes, France

(3)Department of Rheumatology, CHU Nantes, Nantes, France.

\section{Corresponding author:}

François Robin,

16 Boulevard de Bulgarie, 35200 Rennes, France

francois.robin@chu-rennes.fr, +33299284321

Keywords: Lower lumbar radicular pain; caudal hiatus epidural injection; ultrasound-guided 
Lower lumbar radicular pain is a benign and frequent condition [1], mostly induced by disk herniation or osteoarthritis. The management of lower lumbar radicular pain is a public health problem [2], with multimodal management. Lumbar epidural steroid injections are considered as a treatment but their effectiveness remains controversial, with conflicting results [3-5]. Injection via the caudal hiatus route $(\mathrm{CH})$ under ultrasound (US) guidance has gained popularity because of accessibility or US equipment, absence of irradiation, feasibility and very few complications reported [6].

A pragmatic prospective observational two-center (Rennes and Nantes University Hospitals) study was performed to evaluate the effectiveness of a single steroid (cortivazol) epidural injection delivered under US guidance via the $\mathrm{CH}$ on lower lumbar radicular pain. The primary outcome for success was achieving a numerical pain rating scale score (NPRS $\leq 3 / 10$ at day 30 (D30) after epidural injection. The secondary endpoints were achieving a NPRS $\leq 3 / 10$ at D30 without opiates and NSAIDs, level of analgesic and NSAIDs consumption, absence from work and occurrence of adverse events. Factors related to efficacy were not well established.

One hundred and fifty patients were enrolled [Appendix A, Table S1 and Figure S1; See the supplementary material associated with this article online]. Compared to the baseline $(10 \%$ of patients with NPRS score $\leq 3 / 10$, not excluded in the final analysis), $31 \%$ at 10 days (D10) post-injection $(p<0.001)$ and to $37 \%$ at D30 $(p<0.05)$ reported a NPRS score $\leq 3 / 10$ (Figure 1$)$. The proportion of patients achieving this objective without consuming opioids or NSAIDs was $23 \%$ at D10 and D30 $(p<0.001)$. Opioid and NSAIDs consumption decreased significantly between baseline, D10 and D30. During follow-up, patients did not report any adverse events. We found no clear predictive factors for the efficacy of epidural injections at D10 and D30 after injection (Table 1).

Previous studies using the $\mathrm{CH}$ found some conflicting results on steroid injection effectiveness on radicular pain $[7,8]$, mainly because the heterogeneity of the populations studied and the frequency of monitoring (first evaluation at 6 weeks [7] or 3 months [8]). In our study, consistent with Nandi et al. [9] study, epidural injections of steroids through the $\mathrm{CH}$ appeared to be effective in relieving lower lumbar radicular pain induced by herniated disk on a native spine pain in the short term (1 month). It was an important pragmatic point because the first and main objective of the epidural injection is to alleviate as soon as possible severe or resistant pain-in a pathology frequently associated with spontaneous favorable medium-term evolution [10]. Similar to the literature reported, we were unable to identify any predictive factors for the efficacy of $\mathrm{CH}$ injections [3]. No serious adverse events during the follow-up were observed, confirming the safety of this route. 
In conclusion, a single $\mathrm{CH}$ epidural steroid injection under US guidance improved significantly the radicular NPRS in about one-third of the patients. Patients and clinicians should be aware of the results when discussing therapeutic options for this condition. The usefulness of a second injection 10 days after the first injection for patients who are insufficiently responsive to the first injection should be specifically investigated.

Competing interests: No conflict of interest in relation to the results of this work is reported by all authors.

Ethical approval information: All patients were informed of the objectives and procedure of the study and gave their consent. The study was approved by the ethics committee of Rennes university hospital (Avis $n^{\circ} 18.38$, Oct 2015).

Acknowledgements: All authors would like to thank all patients who participated in this study.Funding: This study did not receive any funding.

\section{Appendix A. Supplementary data}

Supplementary data (Table S1, Figure S1) associated with this article can be found in the online version at ... 


\section{References}

[1] Frymoyer JW. Lumbar disk disease: epidemiology. Instr Course Lect 1992;41:217-23.

[2] Tubach F, Beauté J, Leclerc A. Natural history and prognostic indicators of sciatica. J Clin Epidemiol 2004;57:174-9. doi:10.1016/S0895-4356(03)00257-9.

[3] Spaccarelli KC. Lumbar and caudal epidural corticosteroid injections. Mayo Clin Proc 1996;71:169-78. doi:10.1016/S0025-6196(11)64510-2.

[4] Manchikanti L, Singh V, Cash KA, Pampati V, Damron KS, Boswell MV. A randomized, controlled, double-blind trial of fluoroscopic caudal epidural injections in the treatment of lumbar disc herniation and radiculitis. Spine 2011;36:1897-905. doi:10.1097/BRS.0b013e31823294f2.

[5] Carette S, Leclaire R, Marcoux S, Morin F, Blaise GA, St. -Pierre A, et al. Epidural corticosteroid injections for sciatica due to herniated nucleus pulposus. N Engl J Med 1997;336:1634-1640.

[6] Blanchais A, Le Goff B, Guillot P, Berthelot J-M, Glemarec J, Maugars Y. Feasibility and safety of ultrasound-guided caudal epidural glucocorticoid injections. Joint Bone Spine 2010;77:440-4. doi:10.1016/j.jbspin.2010.04.016.

[7] Iversen T, Solberg TK, Romner B, Wilsgaard T, Twisk J, Anke A, et al. Effect of caudal epidural steroid or saline injection in chronic lumbar radiculopathy: multicentre, blinded, randomised controlled trial. BMJ 2011;343:d5278. doi:10.1136/bmj.d5278.

[8] Park KD, Kim TK, Lee WY, Ahn J, Koh SH, Park Y. Ultrasound-Guided Versus Fluoroscopy-Guided Caudal Epidural Steroid Injection for the Treatment of Unilateral Lower Lumbar Radicular Pain: Case-Controlled, Retrospective, Comparative Study. Medicine (Baltimore) 2015;94:e2261. doi:10.1097/MD.0000000000002261.

[9] Nandi J. A Randomized Controlled Clinical Trial to Determine the Effectiveness of Caudal Epidural Steroid Injection in Lumbosacral Sciatica. J Clin Diagn Res 2017. doi:10.7860/JCDR/2017/21905.9392.

[10] Andersson GB. Epidemiological features of chronic low-back pain. The Lancet 1999;354:581-585. 
Figure 1: Epidural injection efficacy on root pain, antalgics consumption and professional activity. Difference compared to baseline with $\S=p<0.05$ and $\#=p<0.01$ ). 


\section{Figr-1}

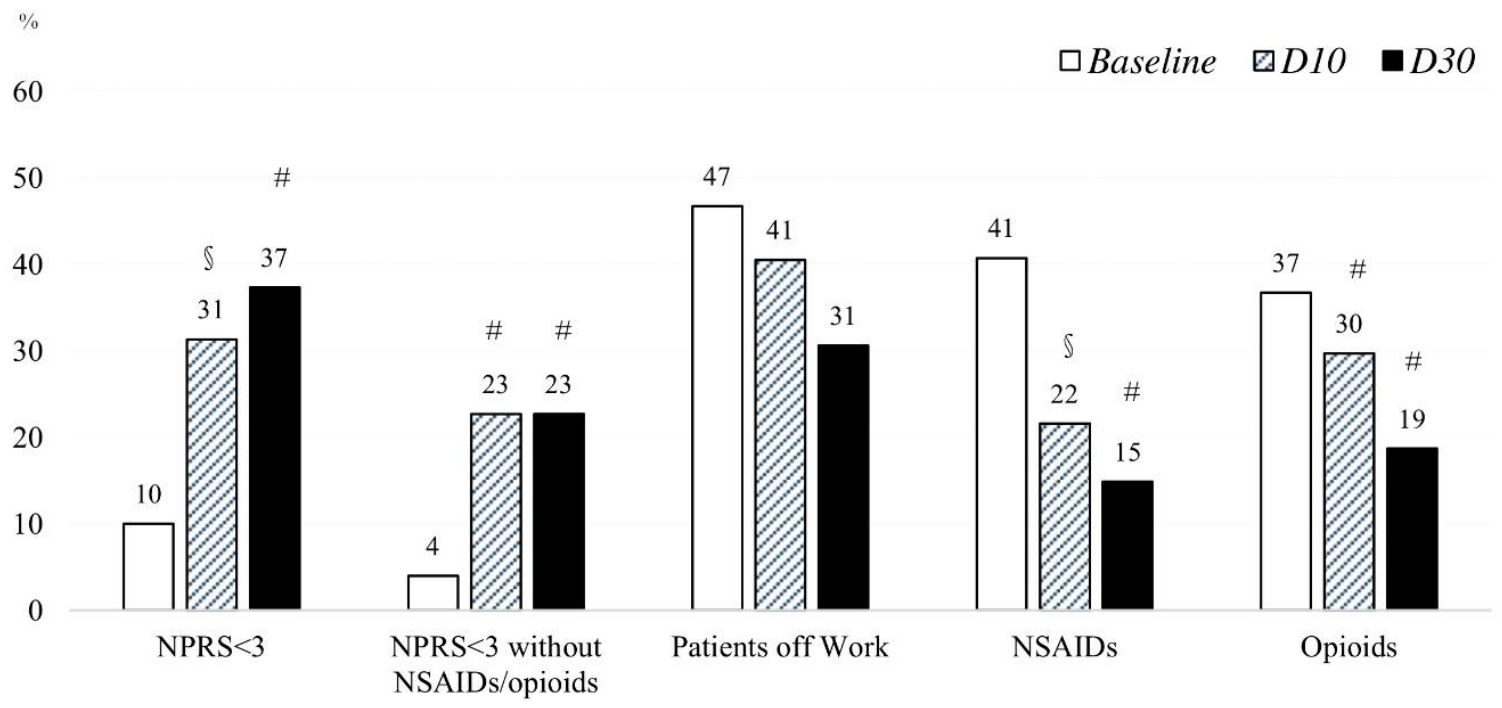




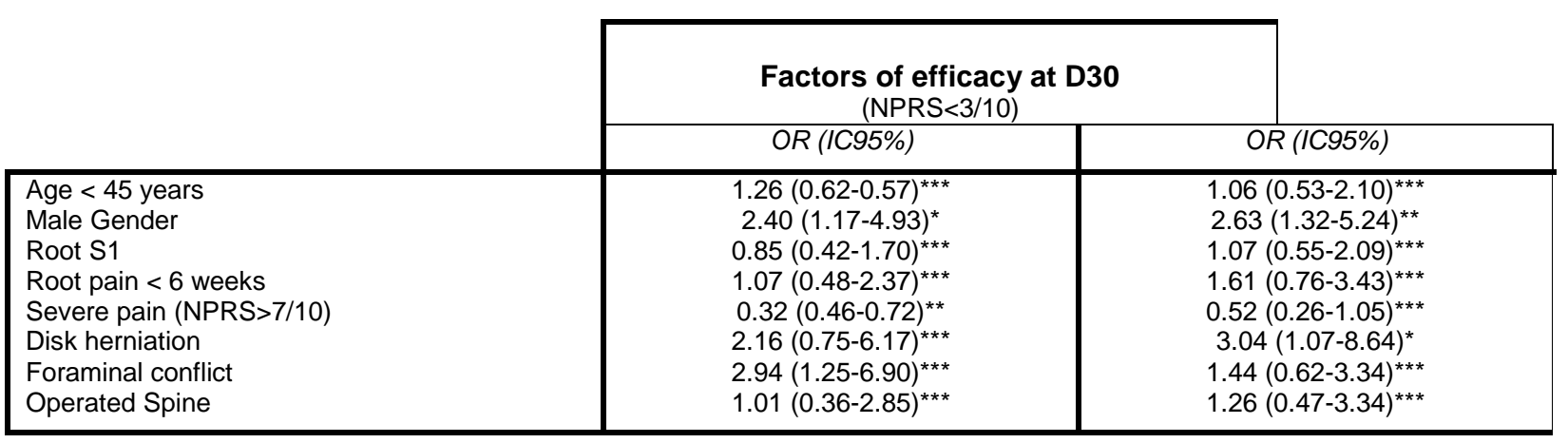

${ }^{*} p<0.05 ;{ }^{* *} p<0.01 ;{ }^{* *}$ NS

Table 1: Factors associated with the efficacy of cortivazol epidural injection via the $\mathrm{CH}$ under ultrasound at D10 and D30. 